\title{
Refugee health clinics grapple with demand
}

$\mathrm{W}$

hen Canada opened its doors to more than 25000 Syrian refugees, their welcome to a new home included access to health care. Living up to that promise has put serious demands on many refugee health clinics.

In Halifax, the Transitional Health Clinic for Refugees saw roughly 180 patients in its first 18 months of operation. Then, between the end of December and mid-March, the 12 volunteer doctors saw 694 patients.

"We've seen, in effect, every government-assisted refugee that came [to Halifax] in the Syrian influx," says Dr. Mandi Irwin, a family physician and one of three doctors who cofounded the transitional health clinic in 2014. Those numbers won't drop off now that initial health assessments have been completed, she adds. "They are now our patients." However, the increasing demand for services will abate now that the influx of Syrian refugees has arrived. "It will now be steady."

Some 5000 Syrian refugees were welcomed to the Greater Toronto Area. The Crossroads Clinic in the Women's College Hospital in Toronto collaborated with others in the city to arrange four clinics for some 2200 governmentsponsored Syrian refugees. "That was woefully inadequate. We went to 31 clinics within a few weeks," says Dr. Meb Rashid, Crossroads' medical director. "Our goal was to see people within two weeks of arrival, then get them into the primary health care system."

It's not only health clinics for government-assisted refugees that are grappling with increasing demand for their services, which are often provided by volunteers. The patient load increased $300 \%$ at the Community Volunteer Clinic for Medically Uninsured Immigrants and Refugees in Scarborough, Ont. following cuts to the federal government's Interim Fed- eral Health Program in 2012. "We had been seeing 12 to 14 people [a day]. It blew up to 30 to 35 ," said Dr. Paul Caulford, a family physician and cofounder of the clinic.

\section{Refugee patients}

Fortunately, despite the increase in numbers, there has not been a decrease in the time spent with each refugee patient. An initial assessment includes a general check-up and medical history and often minor procedures, vaccines, vision and dental screening. This process takes much longer, notes Irwin in Halifax. "We saw 1.5 patients an hour. Most family doctors see eight patients an hour."

Moderation is important in initial assessments, says Dr. Kevin Pottie, cochair of the Canadian Collaboration for Immigrant and Refugee Health. "They may be refugees, but they are not necessarily sick. You do not need to run every test."

Indeed, said Dr. Otmar Kloiber, secretary general of the World Medical Association, "initially physicians and administrators believed they would see extra ordinary amounts of diseases like TB. This is not the case."
Still, physicians working in refugee clinics must be prepared for the atypical. Pottie notes that the immigrant families in his practice are often much larger than Canadian families. "Big families throw us off. We're not used to $9,10,12$ in a family anymore."

Physicians also need to prepare themselves for conditions they have likely never encountered, such as a TB abscess on the brain and grenade injuries, says Caulford.

Language may be a barrier when treating this population. Family members often help with interpretation, "but this can be probematic if the patient wants to talk about something like sexual assault," says Kloiber.

A new website and app, iamsick.ca, helps locate health providers fluent in a specific language. "When connecting newcomers to doctors who speak their language you are connecting them to much more than an interpreter," says Nouhaila Chelkhaoui, who is leading the company's Syrian refugee initiative.

There is widespread agreement that, ultimately, "the most important thing is to get those people as soon as possible integrated into the mainstream system," says Kloiber.

That is the goal of the Halifax clinic. "Our goal is to transition patients out to a regular family doctor essentially with a health passport," says Irwin. The "passport" signifies that patients are ready to start seeing a family doctor in their community. It indicates, for example, that they have been vaccinated, they have some understanding of how a doctor's appointment works and they know how to use a drugstore. - donalee Moulton, Halifax, NS

CMAJ 2016. DOI:10.1503/cmaj.109-5288 